\title{
Synthesis and inhibition corrosion effect of two thiazole derivatives for carbon steel in
}

$1 \square \mathrm{M} \mathrm{HCl}$

\author{
O. Benali ${ }^{1 *}$, M. Zebida ${ }^{1,2}$, U. Maschke ${ }^{3}$
}

${ }^{1}$ Laboratory of Chemistry: Synthesis, Properties and Applications, University of Saida -Dr.

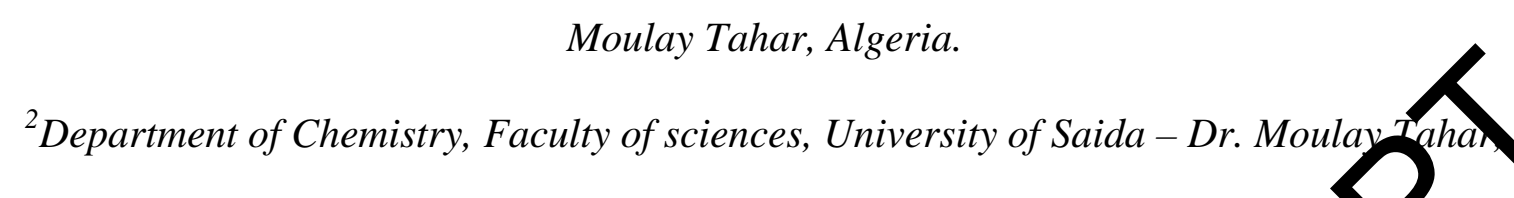

Algeria.

${ }^{3}$ Unité Matériaux et Transformations: Ingénierie des systèmes polymèr

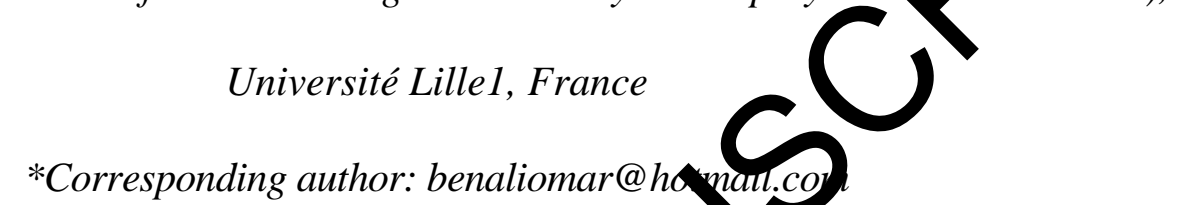

*Corresponding author: benaliomar@homant.co

Inhibition of C38 carbon steel corrosion by and 4-methyl-2-(methylthio)-3- phenylthiaz-3-1um (ST1) in $1 \mathrm{M} \mathrm{HCl}$ was investigated by weight loss and electrochemic netho s. All of the data obtained reveal that the two compounds act as good in 1 bitu this media. At optimized concentration TO1 and ST1 showed the highest mibition efficiency of $98.8 \%\left(2.10^{-4} \mathrm{M}\right)$ and $93.86 \%\left(10^{-3} \mathrm{M}\right)$ respectively. Parion curves show that inhibitor molecules act as mixed type inhibitors. The imped nce suay showed that an increase in the concentration of the two inhibitors is accon panie by an increase in polarization resistance and a decrease in double layer caflance. The Langmuir isotherm very well describes the adsorption of inhibitors to the surface of the corroding metal and the thermodynamic parameters showed that the adsorption of the two compounds was strong and chemical nature. X-ray photoelectron spectroscopy (XPS) confirms and describes the absorption of inhibitors under investigation on the metal surface. 
Keywords: Corrosion inhibition; C38 carbon steel; HCl; thiazole derivatives, XPS

\section{Introduction}

Carbon steel is one of the most widely used metals in the automotive industry, machinery, construction structures, among many other uses. This material has been extensively studied as a model for corrosion inhibition. This is due to the fact that carbon steel corrodes very easily in different environments, but if we talk about an acidic medium which is very corrosive, he corrosion of carbon steel increases considerably [1-4]. In general, the inhibit s a organic compounds in whose structures are oxygen, sulfur, nitrogen and phos auroms and unsaturated bonds together with aromatic rings. Thiazole-type comp unds have been proven to be potent corrosion inhibitors. This is due to their strong atsorptio susceptibility to metal surfaces in aggressive media via their polar groups and thete tial for complexing with the metal surface. In addition, they exhibit differont a ricultural, industrial and biological properties such as anticancer, antiviral, antibac vantifungal, etc. [5-18].

All of these properties have manifested their ntl-toxic character. They also possess abundant pie-electrons and unshared electon airs on the nitrogen atom, which can interact with any metal's d-orbitals to proy a a rective film1 [13-14]. Thus in recent years research on derivative thiazole ip 1by ors has been a major topic. Researchers have made many efforts to

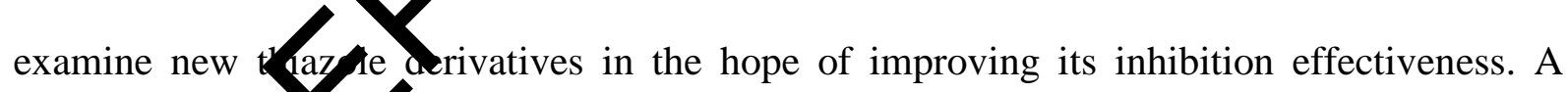
common ro ute fo enhancing a given heterocycle's corrosion inhibition efficiency is to alter its str cture with different moieties or functional groups [15-18].

Th is work is focused at synthesizing two thiazolic derivatives : 4-methyl-3-phenyl-2(3H)thiazolethione (TO1) and 4-methyl-2-(methylthio)-3- phenylthiazol-3-ium (ST1) and study their inhibition efficiency as inhibitors for $\mathrm{C} 38$ carbon steel in $1 \mathrm{M} \mathrm{HCl}$ solution, using electrochemical methods, weight loss measurement and XPS surface study.

\section{Experimental Section}




\subsection{Materials}

\subsubsection{Composition of C38 Sample.}

The pieces of steel sheet (used as working electrode and for weight loss experiments) were prepared from C38 carbon steel, where the composition and method of preparation was given in our already published work [14].

\subsubsection{Solutions.}

The concentration of the used inhibitors ranged from $10^{-6} \mathrm{M}$ to $10^{-3} \mathrm{M}$ in $1 \mathrm{M}$ repared from $37 \% \mathrm{HCl}$ in distilled water).

\subsubsection{Synthesis of corrosion inhibitors}

\section{a) 4-methyl-3-phenyl-2(3H)-thiazolethione (TO1)}

Aniline (18.5 mL, $0.2 \mathrm{~mol})$ was added dropwise on a maf $\mathrm{CS}_{2}(14.5 \mathrm{~mL}, 0.2 \mathrm{~mol})$ and $24 \mathrm{~mL}$ of $\mathrm{NH}_{4} \mathrm{OH}$, stirred at $0^{\circ} \mathrm{C}$. After stirring for 2 sur at room temperature, the mixture was filtered and washed with $\mathrm{Et}_{2} \mathrm{O}(3 \times 25$ give the yellow dithiocarbamate $(30 \mathrm{~g}$, 80\%). 1-Chloro-2-propanone ( $9 \mathrm{~mL}, 0.1 \mathrm{mo}$ eq) was added to a suspension of (18.6 $\mathrm{g}$, $0.1 \mathrm{~mol})$ of the dithiocarbamate al et anol $(20 \mathrm{~mL})$. After stirring for 2 hours at r.t., 0.5 $\mathrm{mL}$ of $\mathrm{HCl}$ (36\%) were ar aed $\mathrm{d}$ he mixture was refluxed for 3 hour. After filtration, the solid was washed water $(3 \times 5 \mathrm{~mL})$ and dried to give (TO1) $(15.13 \mathrm{~g}, 73 \%, \mathrm{mp}=$ $146^{\circ} \mathrm{C}$ ). Detaile re tion mechanism is presented in figure 1a and NMR spectra of TO1 is presented i figur ib.
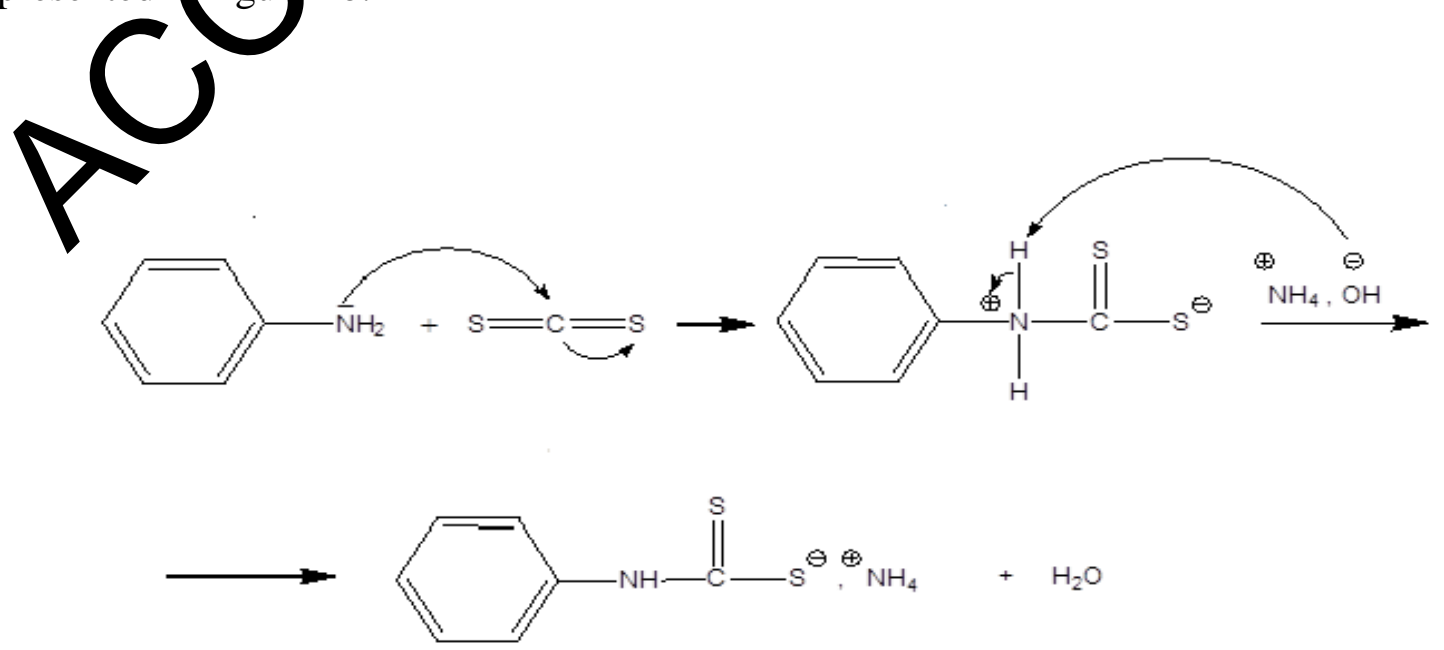

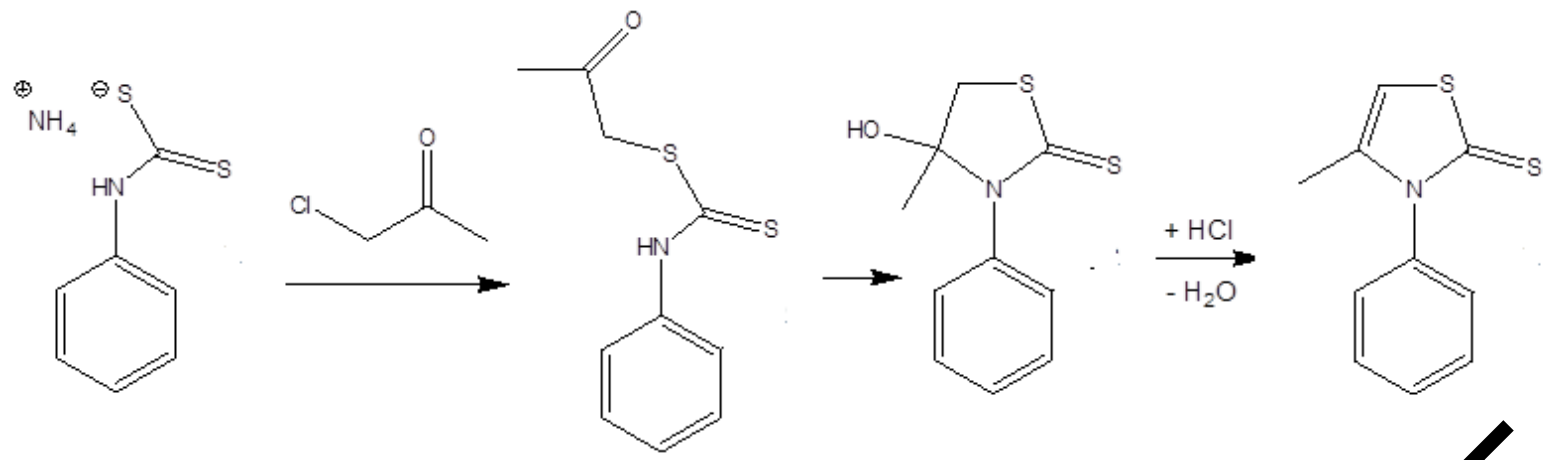

Figure 1a. Synthesis of 4-methyl-3-phenyl-2(3H)-thiazolethione (TO1

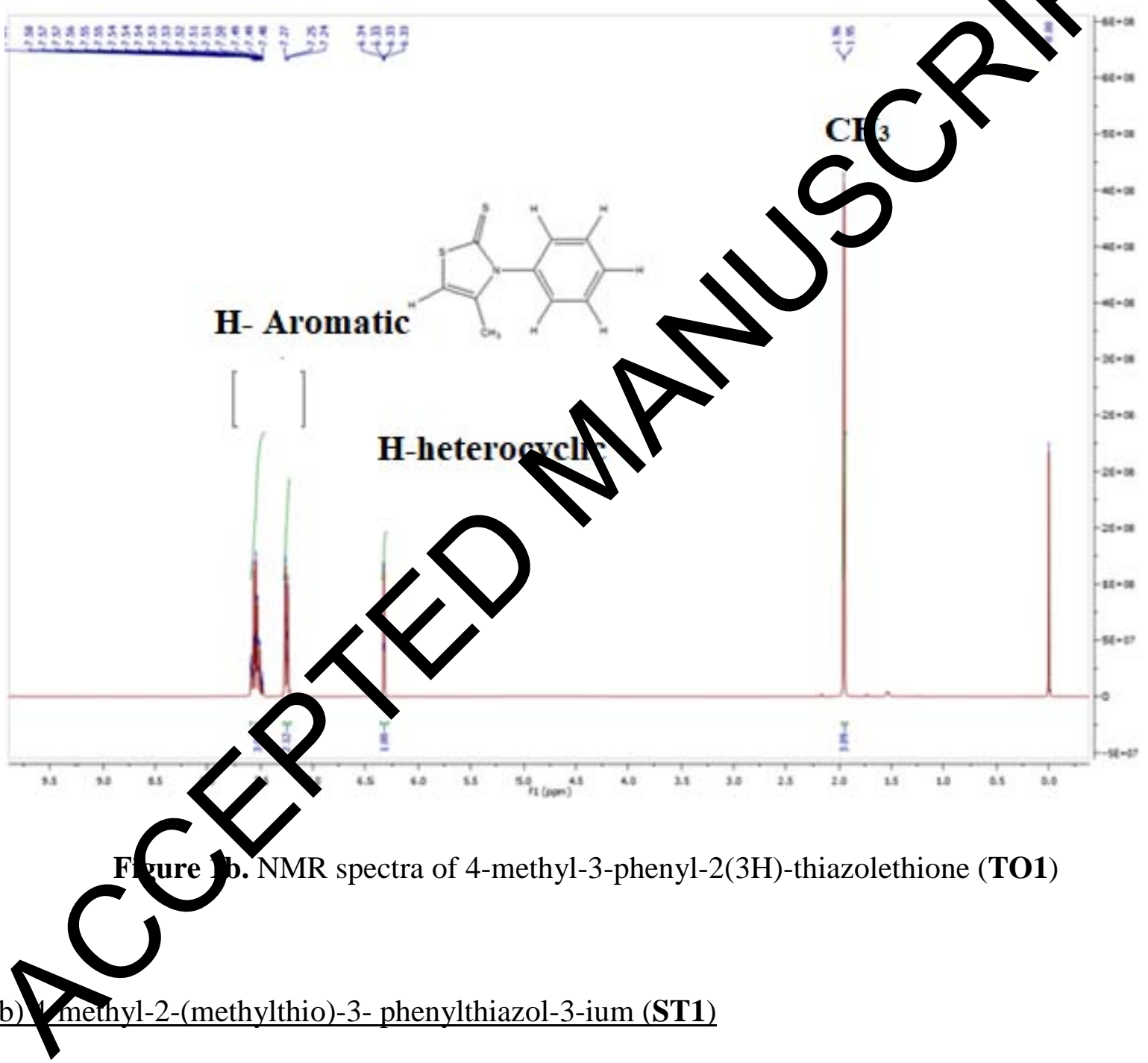

The method adapted to the synthesis of this thiazolium salt (ST1), provides the condensation of thiazolin-2-thione, with the alkyl iodine in acetonitrile with magnetic stirring at room temperature according to the alkylation method of thiazol-2-thione described by literature [2021] as shown in figure 1c and NMR spectra of ST1 is presented in figure1d. 
In a $200 \mathrm{ml}$ monocolumn flask, $100 \mathrm{mg}$ (10 mmol, $2 \mathrm{~g}, 1 \mathrm{eq})$ of thiazolin-2-thione are solubilized in acetonitrile $(50 \mathrm{ml})$. Then $6.84 \mathrm{ml}$ (11 eq) of methyl iodide is added using a syringe. The solution is stirred magnetically for $24 \mathrm{~h}$ at room temperature. The product is obtained by sinter filtration and dried $\left(85 \%, \mathrm{mp}=220^{\circ} \mathrm{C}\right)$.<smiles>Cc1csc(=S)n1-c1ccccc1</smiles>
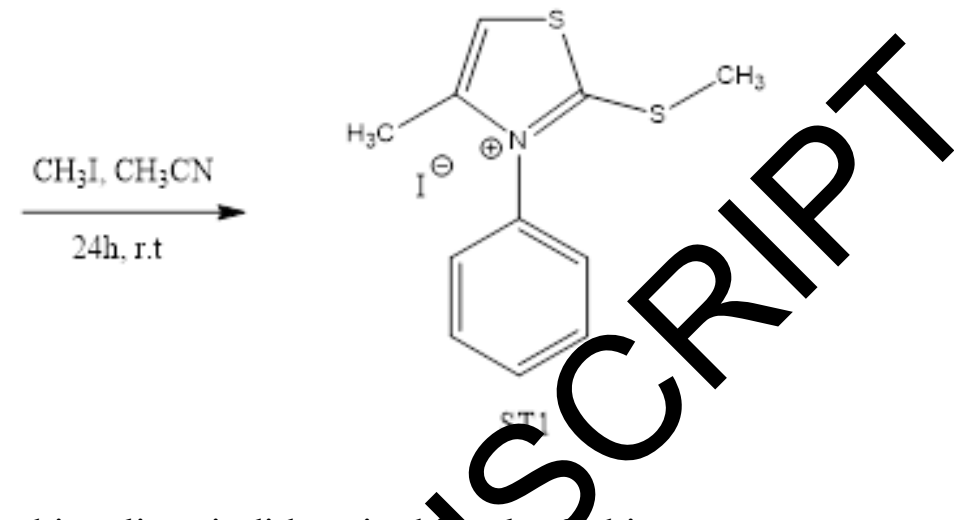

Figure 1c. Synthesis thiazolium iodides via thisol-thione.

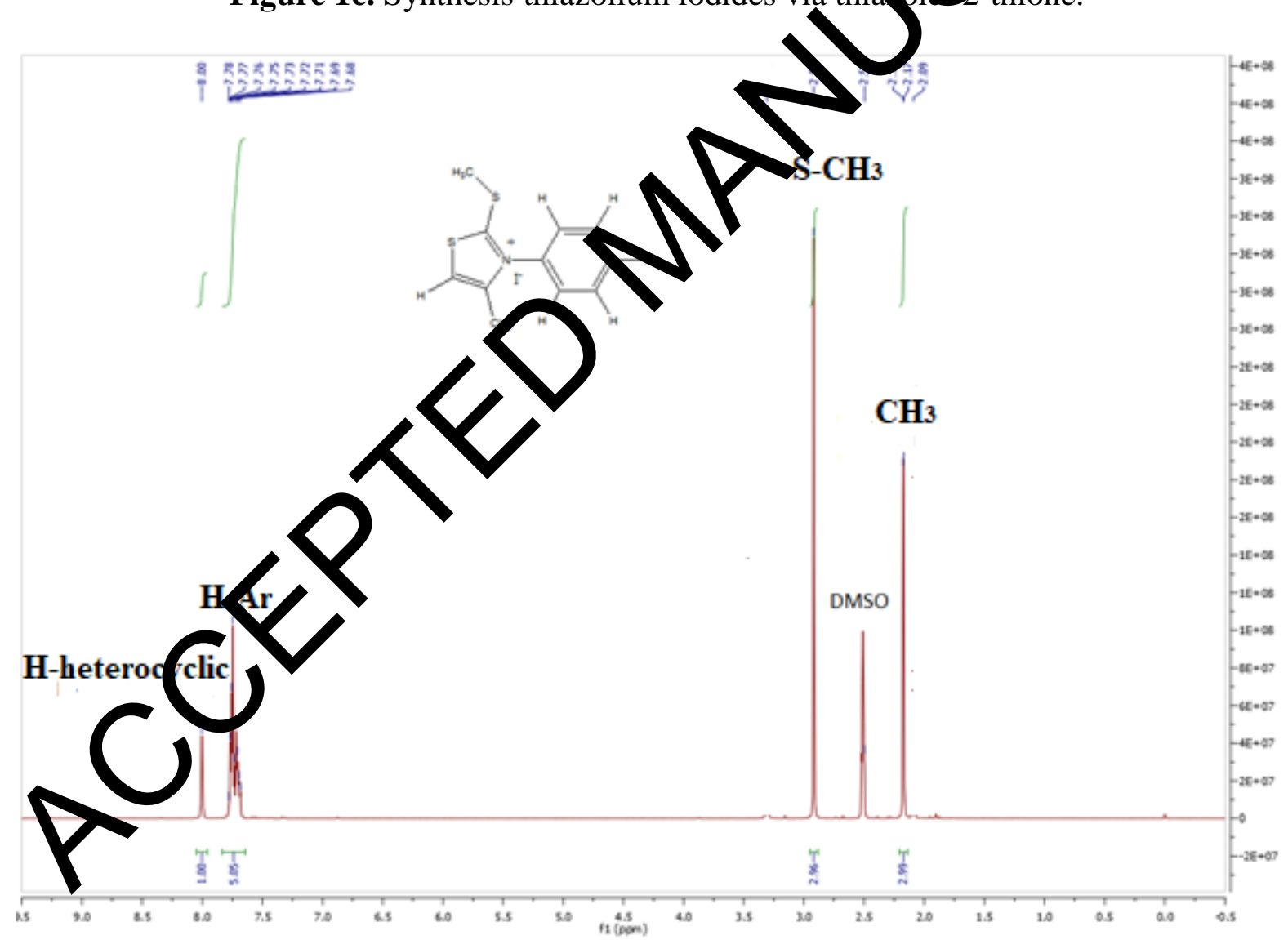

Figure 1d. NMR spectra of 4-methyl-2-(methylthio)-3- phenylthiazol-3-ium (ST1) 


\subsection{Methods}

For weight loss studies the dimension of C38 steel is $1.5 \mathrm{~cm} \times 1.5 \mathrm{~cm} \times 0.2 \mathrm{~cm}$. The measurements were carried out at $30^{\circ} \mathrm{C}$ for $1 \mathrm{~h}$ of immersion into $100 \mathrm{~mL}$ of $1 \mathrm{M}$ hydrochloric acid in the absence and the presence of various concentrations of inhibitors.

After immersion, the samples were washed, degreased with acetone and weighed. All the manipulations were repeated three times in order to have reproducibility. Equation (1), and (3) give the procedure for calculating the corrosion rate (C.R), the inhibiry fficiency (IE\%) and the recovery rate ( ) [4]:

where $\Delta \mathrm{W}=$ weight loss $(\mathrm{mg}), \mathrm{S}=$ area of specimen $\left(\mathrm{cm}^{2}\right)$ and

\section{1}

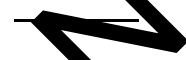

where C.R and C.R' are the corrosion rate $m$ and without inhibitor, repectively.

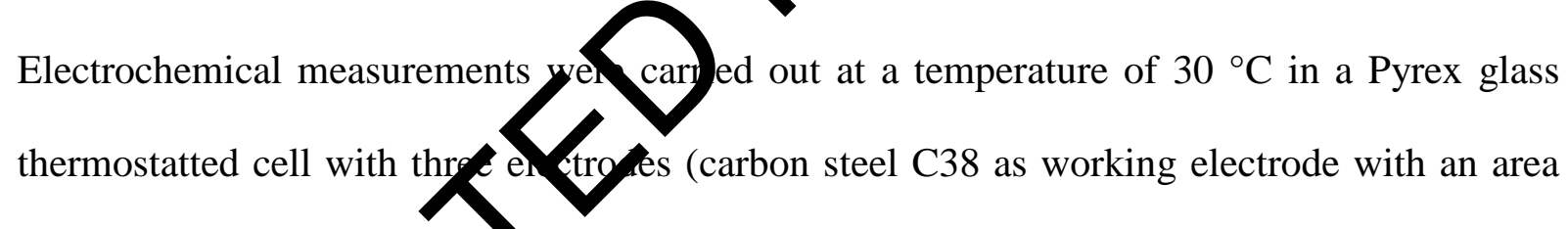
of $1 \mathrm{~cm}^{2}$, platinum $\mathrm{s}$ oun r-electrode $\left(1 \mathrm{~cm}^{2}\right)$ and a saturated calomel electrode as reference electrose solution is subjected to stirring and azote gas bubbling. The Solartron strurgens SI 1287 potentiostat assisted by a personal computer via a GPIB interf ce any the CorrWare 2.80 software were used to perform the electrochemical tests and colese experimental data. The steel sample was allowed to corrode freely and its open circuit potential (OCP) for 1 hour (sufficient time to have the stable potential regime). The last OCP value recorded corresponds to the corrosion potential $\left(\mathrm{E}_{\text {corr }}\right)$ of the working electrode.

The inhibition efficiency (IE \%) was calculated using the following equation: 
where 0 and ihn are corrosion current without and with inhibitor, respectively.

AC impedance measurements were performed with the same electrochemical system using ZPlot 2.80 and ZView 2.80 software to fit the spectra obtained. The system was excited with alternating current with frequency range from $10^{5} \mathrm{~Hz}$ to $10^{-2} \mathrm{~Hz}$ and a peak-to-peak amr itude of $10 \mathrm{mV}$ with 10 points per decade. All EIS diagrams were registered at $\mathrm{E}_{\text {corr }}$ pote 4 tia The values of charge transfer resistance were used to calculate the inhibitig fincien $\left(\mathrm{EI}_{\mathrm{Rt}}\right.$ (\%)) as previously described [4].

The detailed description of the method X-ray photoelectron spect treatment of the results is given in our published paper [4]

\section{Results and Discussion}

\subsection{Weight loss measurements}

The table 1 gives the values of the corrosing rate inhibition efficiency of TO1 and ST1 in $1 \mathrm{M} \mathrm{HCl}$. An overview on this tabl cleary notice that the both inhibitors are effective against corrosion, even at lo ration and the the efficacies are related to the inhibitor concentrations

Maximum IE\% of ex Compound was achieved at $2 \cdot 10^{-4} \mathrm{M}$ for TO1 and $10^{-3} \mathrm{M}$ for ST1. The use of lown copentration for the TO1 inhibitor can be explained in terms of nonbinding in the molecule. While TO1 has two unbonded electron pairs, the ST1 molecule has on pair. This fact indicates a greater adsorption and attraction to the metal of the TO inhibitor.

Table 1. Weight loss results of C38 carbon steel in presence of TO1 and ST1 in $1 \mathrm{M} \mathrm{HCl}$

\begin{tabular}{ccc}
\hline Conc. & Corrosion rate & IE \\
$(\mathrm{M})$ & $\left(\mathrm{mg} \cdot \mathrm{cm}^{2} \cdot \mathrm{h}^{-1}\right)$ & $(\%)$ \\
\hline
\end{tabular}




\begin{tabular}{cccc} 
& Blank & 1.00 & --- \\
\hline & $10^{-6}$ & 0.61 & 39 \\
\hline TO1 & $10^{-5}$ & 0.42 & $\mathbf{5 8}$ \\
& $10^{-4}$ & 0.22 & $\mathbf{7 8}$ \\
\hline ST1 & $2.10^{-4}$ & 0.07 & $\mathbf{9 3}$ \\
& $10^{-6}$ & 0.48 & $\mathbf{5 2}$ \\
& $10^{-5}$ & 0.30 & $\mathbf{7 0}$ \\
\hline & $10^{-4}$ & 0.24 & $\mathbf{7 6}$ \\
\hline
\end{tabular}

Moreover, we note from the same table that the STre efficient compared to the TO1 at the concentration lower than $10^{-4} \mathrm{M}$. This is do the strong adsorption at low concentration of the compound TO1 ampare to ST1.

\subsection{Electrochemical expenent}

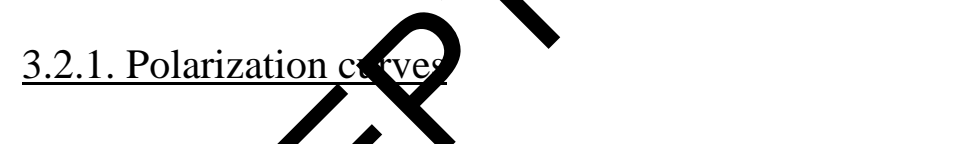

Under the same nditions as the gravimetric measurements $\left(\mathrm{t}=1 \mathrm{~h}\right.$ and $\left.\mathrm{T}=30^{\circ} \mathrm{C}\right)$, the anodic and atho ic polarization curves in the absence and in the presence of both inhibitors at diferent concentrations were obtained (figure $2 a$ and $2 b$ ). The scan rate of the ele rochemical tests is $0.5 \mathrm{mV} / \mathrm{s}$ [22-23]. 


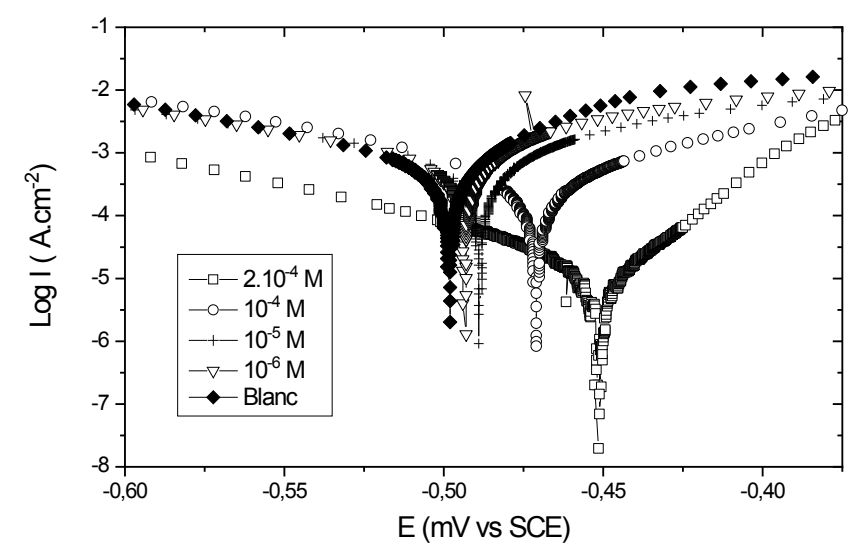

Figure 2a. Potentiodynamic polarization curves for C38 steel in $1 \mathrm{M}$ ACl cantaining different concentrations of TO1. 
- As reported elsewhere, when the values of corrosion potential in the presence of inhibitor is greater than $\pm 85 \mathrm{mV}$ compared to the value in the absence of inhibitor, the inhibitor is considered to be either anodic or cathodic. In this study, the maximum displacement in corrosion potential observed is $\pm 32 \mathrm{mV}$ suggests that the two inhibitors behaves as mixed type of inhibitor [4].

- The values of $b_{c}$ change with increasing concentration of both inhibitors. The rests indicate that the kinetic of the hydrogen evolution reaction is influn by the presence of TO1 and ST1. Such behavior has been largely observatariscussed in the literature [24-25].

- The increase in the concentration of inhibitors has the onseavence of increasing their inhibition efficiency.

Table 2. Electrochemical potentiodynamic parizaton parameters for C38 steel in $1 \mathrm{M}$ HCl containing TO1 and ST1.

\begin{tabular}{|c|c|c|c|c|c|}
\hline & Conc. & $-E_{c}$ & $\begin{array}{c}-b_{c} \\
(\mathrm{mV} / \mathrm{dec})\end{array}$ & $\begin{array}{c}\mathbf{I}_{\text {corr }} \\
\left(\mathrm{mA} / \mathrm{cm}^{2}\right)\end{array}$ & $\begin{array}{c}\text { IIcorr }_{\text {Icr }} \\
(\%)\end{array}$ \\
\hline & & -498 & 138 & 1115 & ---- \\
\hline & & -494 & 137 & 796 & 28.60 \\
\hline & & -488 & 106 & 500 & 55.15 \\
\hline & $10^{-4}$ & -470 & 52 & 253 & 77.30 \\
\hline & $2.10^{-4}$ & -466 & 73 & 34 & 96.95 \\
\hline & $10^{-6}$ & -477 & 135 & 529 & 52.55 \\
\hline & $10^{-5}$ & -491 & 96 & 348 & 68.78 \\
\hline ST1 & $10^{-4}$ & -473 & 65 & 305 & 72.64 \\
\hline & $5.10^{-4}$ & -486 & 85 & 160 & 85.65 \\
\hline & $10^{-3}$ & -487 & 93 & 70 & 93.72 \\
\hline
\end{tabular}




\subsubsection{The electrochemical impedance spectroscopy (EIS)}

Nyquist Impedance diagrams obtained at $\mathrm{E}_{\text {corr }}$ for $\mathrm{C} 38$ steel in $\mathrm{HCl} 1 \mathrm{M}$ in the absence and in the presence of TO1 and ST1 are given in figure 3 (a and b).

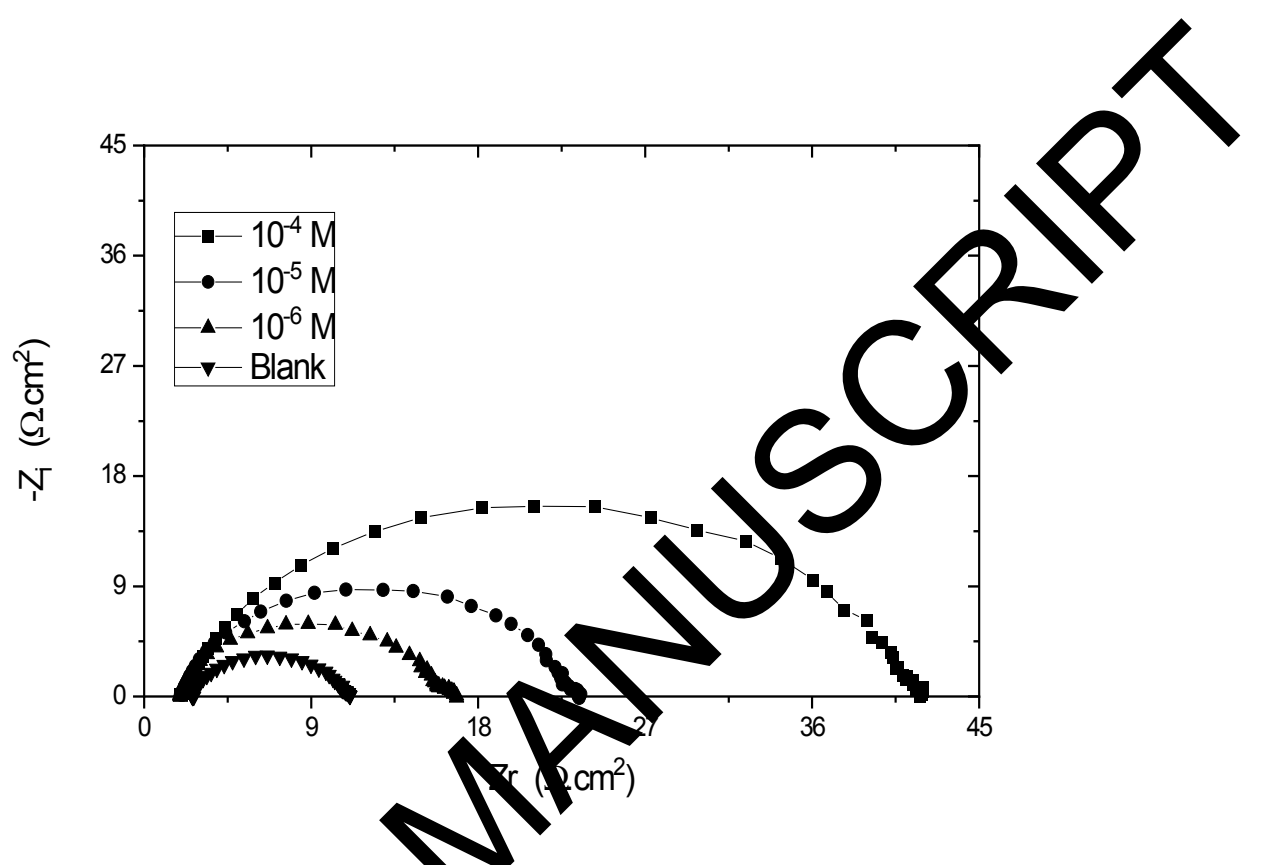

Figure 3a. Nyquist plot for $\mathrm{C} 38$ ste $\mathrm{M} \mathrm{HCl}$ with and without $\mathbf{T O 1}$ at $30^{\circ} \mathrm{C}$.

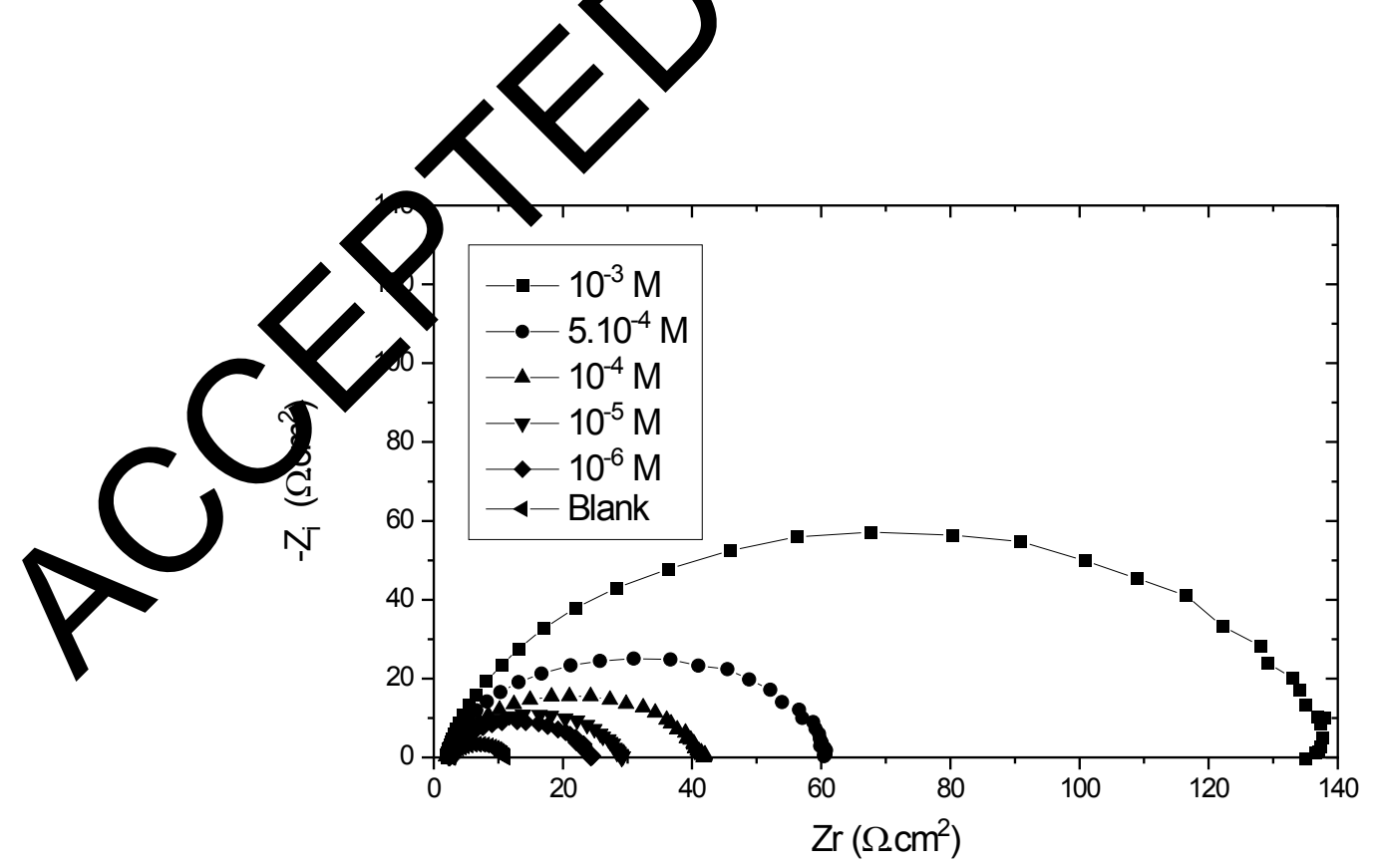

Figure 3b. Nyquist plot for C38 steel in $1 \mathrm{M} \mathrm{HCl}$ solution with and without $\mathbf{S T 1}$ at $30^{\circ} \mathrm{C}$. 
The diagrams are not perfect semicircles and have been attributed to frequency dispersion [26]. This approximately semicircular of impedance diagrams shows that the corrosion phenomenon is controlled by a charge transfer process [6, 27-29]. The increasing of the diameter with increasing of the concentration of the inhibitor indicates the good inhibition effect of our inhibitor [6]. The modeling of these diagrams by the ZView software led ys to propose the following equivalent electrical circuit: an electrolyte resistor in serins wi a charge transfer resistor which in parallel with a CPE (figure 4).

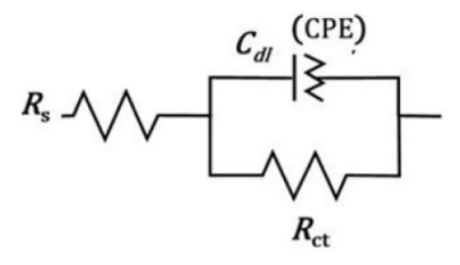

Figure 4. Electrical equivale crov

The obtained results are given in Table 3 (the chare trasfer resistance $R_{t}, n$ values, the CPE (Q) values, the double layer capacitance $C_{d l}$ in pibition efficiency). Ddetailed method of calculating $\mathrm{C}_{\mathrm{dl}}$ values from CPE values is ide to that given in our previous work [4].

It can be seen that the presence the the inhibitors affects the values of $\mathrm{R}_{\mathrm{t}}$ towards the high values and the values of in thesite direction. On the otherhand, in all the case of TO1 and ST1, $\mathrm{n}$ reaches pro ximately the same value of 0.80 . This result can be interpreted as an indication of the of heterogeneity of the metal surface, corresponding to a small depression f the louble layer capacitance semicircle.

These resuly confirmed the obtained results by the above methods.

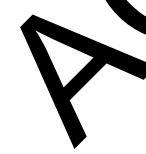

Table 3. Impedance parameters for the corrosion of the system C38 steel / $1 \mathrm{M} \mathrm{HCl}$ in the presence of TO1 and ST1.

\begin{tabular}{cccccc}
\hline Conc. & $\mathbf{R}_{\mathrm{t}}$ & $\mathrm{Q}$ & $\mathrm{n}$ & $\mathrm{C}_{\mathrm{dl}}$ & $\mathrm{EI}_{\mathrm{Rt}}$ \\
$(\mathrm{Mol} / \mathrm{L})$ & $\left(\Omega \cdot \mathrm{cm}^{2}\right)$ & $\left(\Omega^{-1} \cdot \mathrm{cm}^{-2} \cdot \mathrm{s}^{\mathrm{n}}\right)$ & & $\left(\mu \mathrm{F} \mathrm{cm} \mathrm{cm}^{-2}\right)$ & $(\%)$ \\
\hline
\end{tabular}




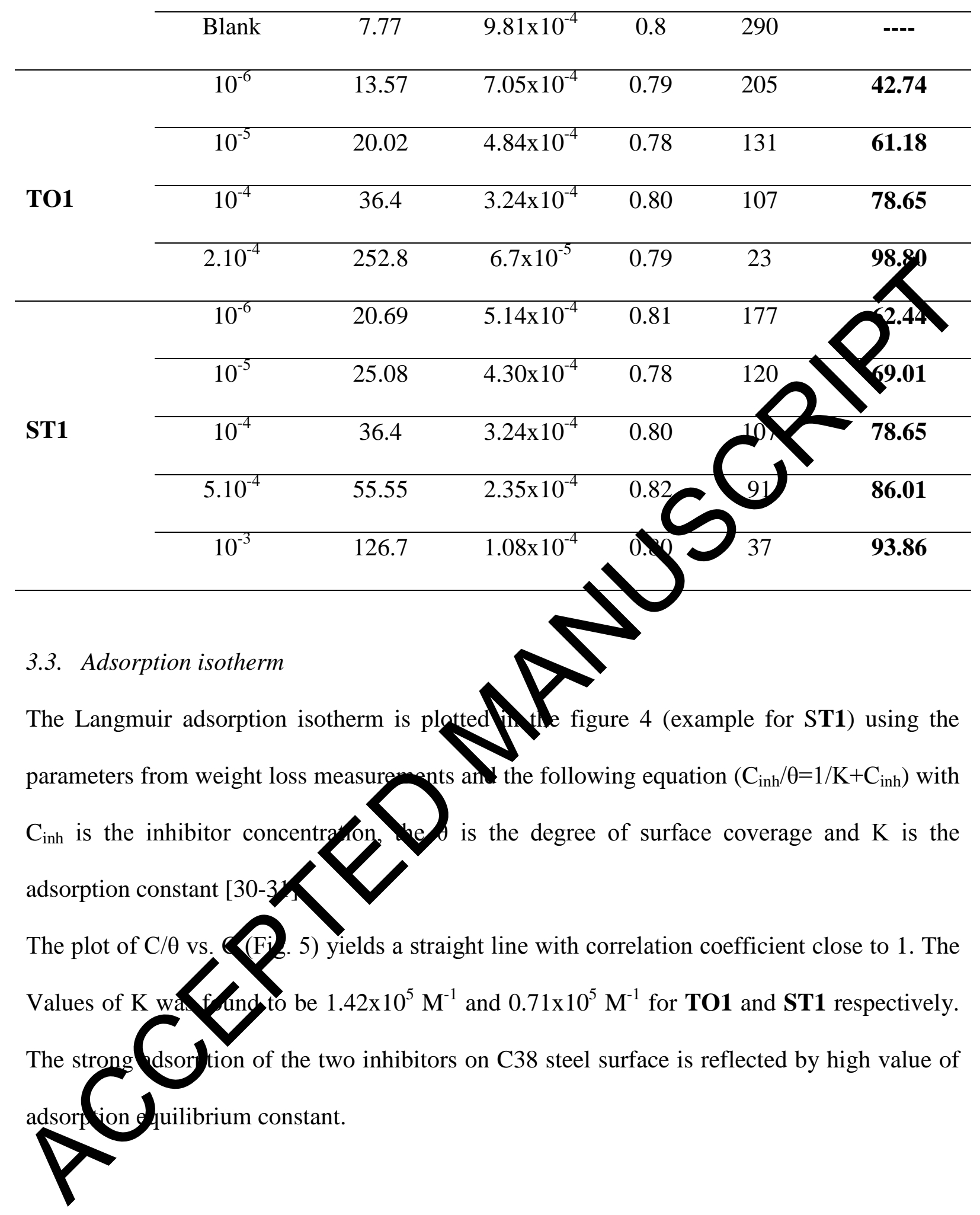




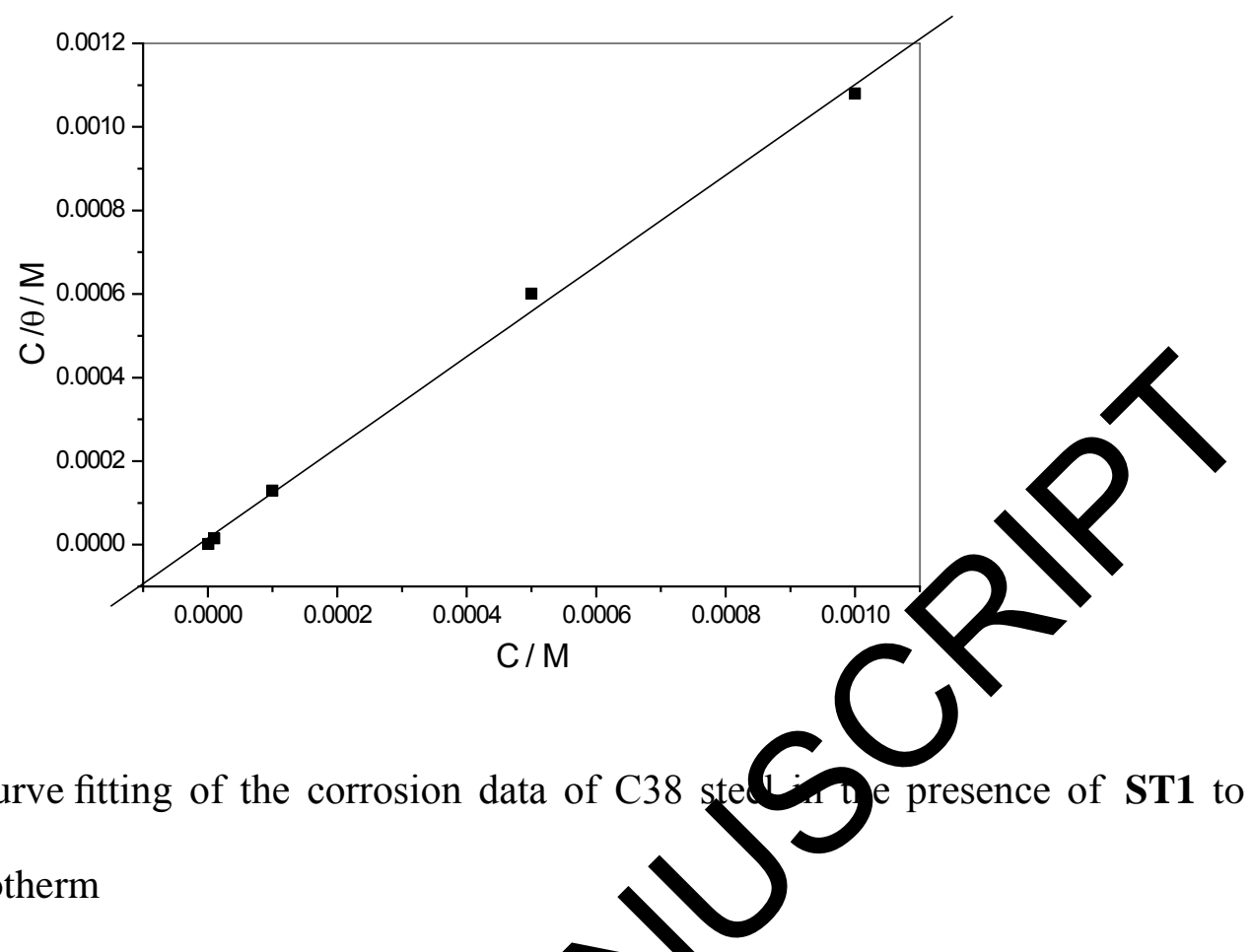

The relation between the standard free enthalpy, $\Delta \mathrm{O}$, and the adsorption constant $(\mathrm{K})$ is given by the relation:

Figure 5. Curve fitting of the corrosion data of C38 ste 12 presence of ST1 to Langmuir isotherm

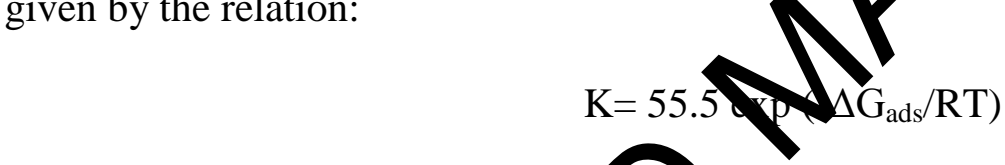

The $\Delta \mathrm{G}_{\mathrm{ads}}$ was calculated as -40.0 /mol nd $-38.05 \mathrm{~kJ} / \mathrm{mol}$ for $\mathbf{S T 1}$ and TO1 respectively. The spontaneous adsorptionoly molecules on the metal surface is clearly identified by the large negative valy of thstandard absorption enthalpy.

According to the itera values of $\Delta \mathrm{G}_{\mathrm{ads}}$ around of $-40 \mathrm{KJ} \cdot \mathrm{mol}^{-1}$ or less are attributed to the formation strons ovalent bonds between the surface of the metal and the free electrons existi $g$ on fine heteroatoms of the inhibitory molecules therefore chemisorption [27, 32-34]. In ovydy, the calculated values of $\Delta \mathrm{G}_{\mathrm{ads}}$ indicate the chemisorptive nature of the adsorption of imhibitors in $1 \mathrm{M} \mathrm{HCl}$ solution [35-36].

The use of thiazole derivatives as corrosion inhibitors has been discussed in several publications [37-42]. Table 4 shows the protection efficiency and $\Delta \mathrm{G}_{\text {ads }}$ obtained of some thiazole derivatives exploited as corrosion inhibitors of steel in a $1 \mathrm{M} \mathrm{HCl}$ medium. Such comparison shows that the values of the standard free enthaply $\left(\Delta \mathrm{G}_{\mathrm{ads}}\right)$ obtained in our study 
and those of the literature are in good agreement where we clearly notice that the majority of thiazole derivatives are strongly adsorbed with a mixed adsorption (physisorption with a tendency to chemisorption).

Table 4. Corrosion protection parameter for thiazole derivatives in $1 \mathrm{M} \mathrm{HCl}$

\begin{tabular}{|c|c|c|c|c|}
\hline Thiazole derivative & $\begin{array}{c}\text { Optimum } \\
\text { Concentration }\end{array}$ & Metal & $\begin{array}{l}\text { Protection } \\
\text { efficiency }\end{array}$ & $\begin{array}{c}-\Delta \mathrm{G} / \mathrm{s} \\
(\mathrm{kJ} / \mathrm{ol}\end{array}$ \\
\hline $\begin{array}{l}\text { 4-methyl-3-phenyl-2(3H)- } \\
\text { thiazolethione [this work] }\end{array}$ & $2 \times 10^{-4} \mathrm{M}$ & $\begin{array}{l}\text { C38 } \\
\text { steel }\end{array}$ & $98.80 \%$ & \\
\hline $\begin{array}{l}\text { thiazol: 4-methyl-2-(methylthio)-3- } \\
\text { phenylthiazol-3-ium [this work] }\end{array}$ & $10^{-3} \mathrm{M}$ & $\begin{array}{l}\text { C38 } \\
\text { steel }\end{array}$ & & \\
\hline $\begin{array}{l}\text { 3-((4-amino-2-methylpyrimidin-5- } \\
\text { yl)methyl)-5-(2-hydroxyethyl)-4- } \\
\text { methylthiazol-3-ium chloride [ } 37 \text { ] }\end{array}$ & $40 \mathrm{ppm}$ & $\begin{array}{l}\text { Carbon } \\
\text { steel }\end{array}$ & & 48 \\
\hline 4-(pyridin-4-yl)thiazol-2-amine [38] & $2 \times 10^{-4} \mathrm{M}$ & & $96.06 \%$ & 36.33 \\
\hline $\begin{array}{c}\text { 2-(2’-hydroxylphenyl)benzothiazole } \\
\text { [39] }\end{array}$ & 50 & & $92.1 \%$ & 34.31 \\
\hline $\begin{array}{c}\text { 2-(2’,5’- } \\
\text { dihydroxyphenyl)benzothiazole [39] }\end{array}$ & & $\begin{array}{l}\text { Mild } \\
\text { steel }\end{array}$ & $51.6 \%$ & 31.87 \\
\hline $\begin{array}{l}\text { (4-benzothiazole-2-yl-phenyl)- } \\
\text { dimethyl-amine [39] }\end{array}$ & & $\begin{array}{l}\text { Mild } \\
\text { steel }\end{array}$ & $96.8 \%$ & 40.80 \\
\hline $\begin{array}{l}\text { 2-(n-hexylamino)-4-(3 -N,N- } \\
\text { dimethylamino-propyl)amino6- } \\
\text { (benzothiazol-2-yl)thio-1,3,5-s- } \\
\text { triazine [40] }\end{array}$ & $M$ & $\begin{array}{c}\text { Carbon } \\
\text { steel }\end{array}$ & $99 \%$ & 34.09 \\
\hline amse-6- & $10^{-3} \mathrm{M}$ & $\begin{array}{c}\text { Carbon } \\
\text { steel }\end{array}$ & $99.3 \%$ & 37.92 \\
\hline ole [40] & $10^{-3} \mathrm{M}$ & $\begin{array}{c}\text { Carbon } \\
\text { steel }\end{array}$ & $57.3 \%$ & 31.72 \\
\hline $\begin{array}{l}\text { 4-(1-hexad cyl-1 r-benzo[d]imidazol- } \\
\text { 2-ylyniazole [41] }\end{array}$ & $10^{-3} \mathrm{M}$ & $\begin{array}{l}\text { Mild } \\
\text { steel }\end{array}$ & $94.5 \%$ & 38.2 \\
\hline $\begin{array}{l}\text { 1,3 dihey adecyl-2-(thiazol-4-yl)- } \\
\text { [41] }\end{array}$ & $10^{-3} \mathrm{M}$ & $\begin{array}{l}\text { Mild } \\
\text { steel }\end{array}$ & $95.3 \%$ & 41.6 \\
\hline $\begin{array}{l}\text { 2-(2-Hydroxyphenyl) } \\
\text { benzothiazole [42] }\end{array}$ & $7.10^{-5} \mathrm{M}$ & $\begin{array}{l}\text { Mild } \\
\text { steel }\end{array}$ & $96.8 \%$ & -37 \\
\hline
\end{tabular}

3.4 Analysis of the organic film formed by XPS photoelectron spectroscopy 
For a better understanding of the inhibition mechanism, we performed photoelectron spectroscopy (XPS) surface analyzes on the organic inhibitor alone and on the organic film adsorbed on the steel surface. In this case we study only the results of TO1 compound.

The characterization by XPS is carried out on the pure TO1 pressed in the form of a pellet $\left(13 \times 2 \times 2 \mathrm{~mm}^{3}\right)$ and on the steel disc immersed for 24 hours in $1 \mathrm{M} \mathrm{HCl}$ in the presence of the optimal concentration of TO1 $\left(2 \times 10^{-4} \mathrm{M}\right)$. The latter is removed from the corrosivemed, rinsed with distilled water and degreased in ethanol under ultrasound and fins y ried. The presence of TO1 on the steel surface was detected based on the signal bactictic of the sulfur atom S2p (Fig. 6b). For comparative purposes, the XPS spectru of of TO1 (Fig. 6a) were also obtained.

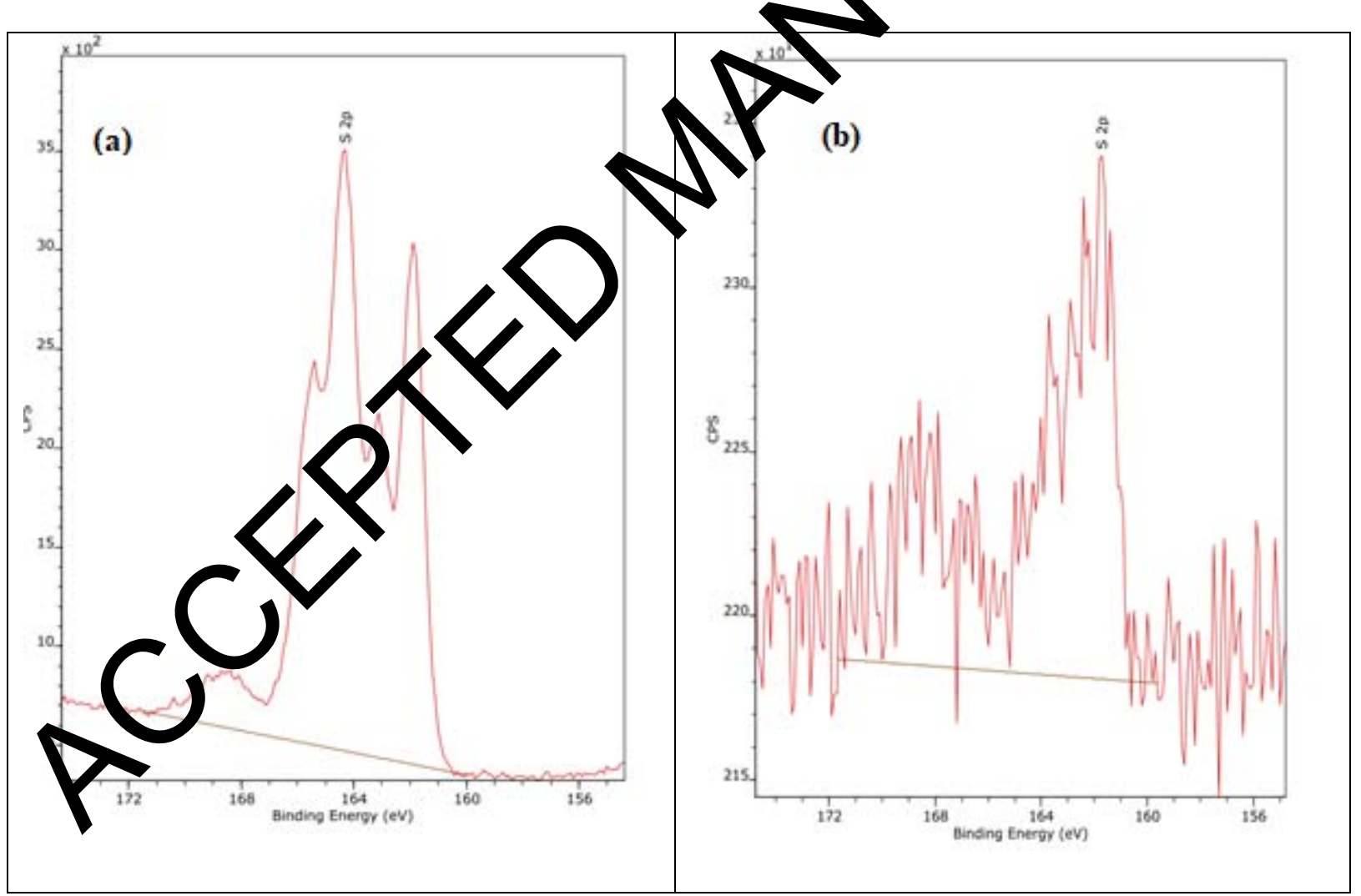

Figure 6. XPS spectrum of S2p for: (a) pure TO1 and (b) the surface of the steel exposed to the solution $\left(2 \times 10^{-4} \mathrm{M} \mathbf{T O 1}+1 \mathrm{M} \mathrm{HCl}\right)$ for $24 \mathrm{~h}$ at $30^{\circ} \mathrm{C}$.

For the surface exposed to hydrochloric acid containing TO1, the large signal from sulfur observed in the binding energy range of 161 to $172 \mathrm{eV}$, can be attributed to several 
components with different binding energies. We observed that the S2p peaks can be deconvolved into several components formed of three doublets. The first deconvolved peak in 162.0 and $163.3 \mathrm{eV}$ is attributed to the oxidation states of sulfur. The doublet at 164.6 and $165.9 \mathrm{eV}$, which is characteristic of the thione function and thiazole (structure $-\mathrm{S}-$ ), shows the presence of TO1 on the steel surface [43] and a doublet at 168.5 and $169.8 \mathrm{eV}$ is dye to the presence of sulphates, $\mathrm{SO}_{4}{ }^{2-}$ which is due to the oxidation of $\mathrm{S}^{2-}$ [44-45].

The surface of the steel covered by chemisorbed TO1 molecules (Fig. 7) revea th existence of a binding energy component to $711 \mathrm{eV}$ (Fe2p 3/2) and at $724 \mathrm{eV}$ (Fe 2 of $\mathrm{Fe}^{3+}$, showing the oxidation of the steel surface [46-47]. The sa Ge fig are shows à little Fe2p peak at $706.6 \mathrm{eV}$ characteristic of $\mathrm{Fe}^{\circ}$ [48-49]. The incre $\mathrm{n} \mathrm{t}$ e Fe2p signal confirms the adsorption and the film formation on the steel surface 517

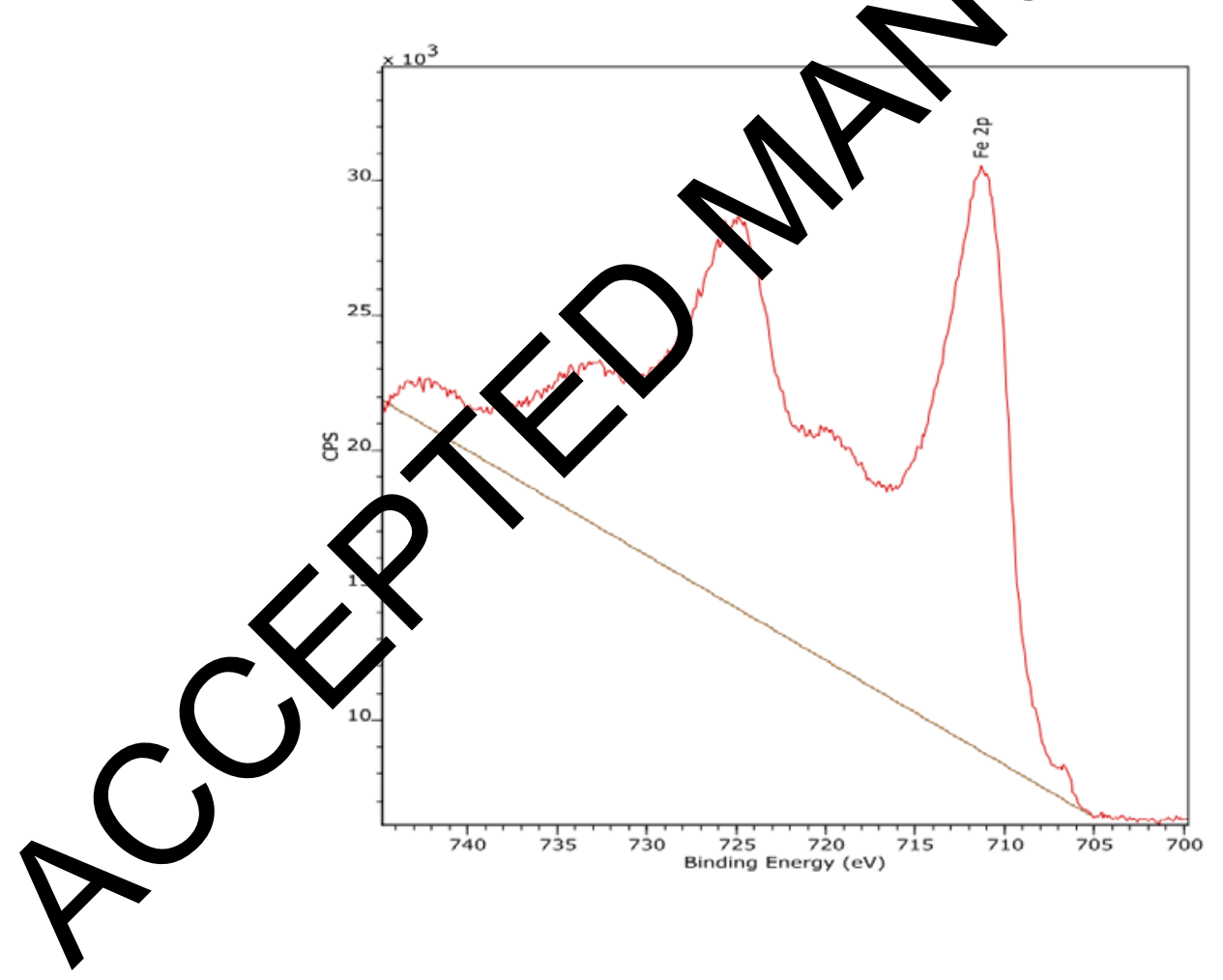

Fig. 7. Spectre Fe2p pour la surface de l'acier oxydée exposée à une solution $\left(2 \times 10^{-4} \mathrm{M}\right.$ $\mathrm{TO} 1+\mathrm{HCl} 1 \mathrm{M})$ pendant $24 \mathrm{~h}$ à $30^{\circ} \mathrm{C}$.

$\mathrm{N}$ 1s spectrum of metal treated with $\mathrm{TO} 1$ in $1 \mathrm{M} \mathrm{HCl}$ shows one peak located at around 399 $402 \mathrm{eV}$ (Fig. 8). This peak can be partly associated to =N- structure in the thiazole ring [52]. 


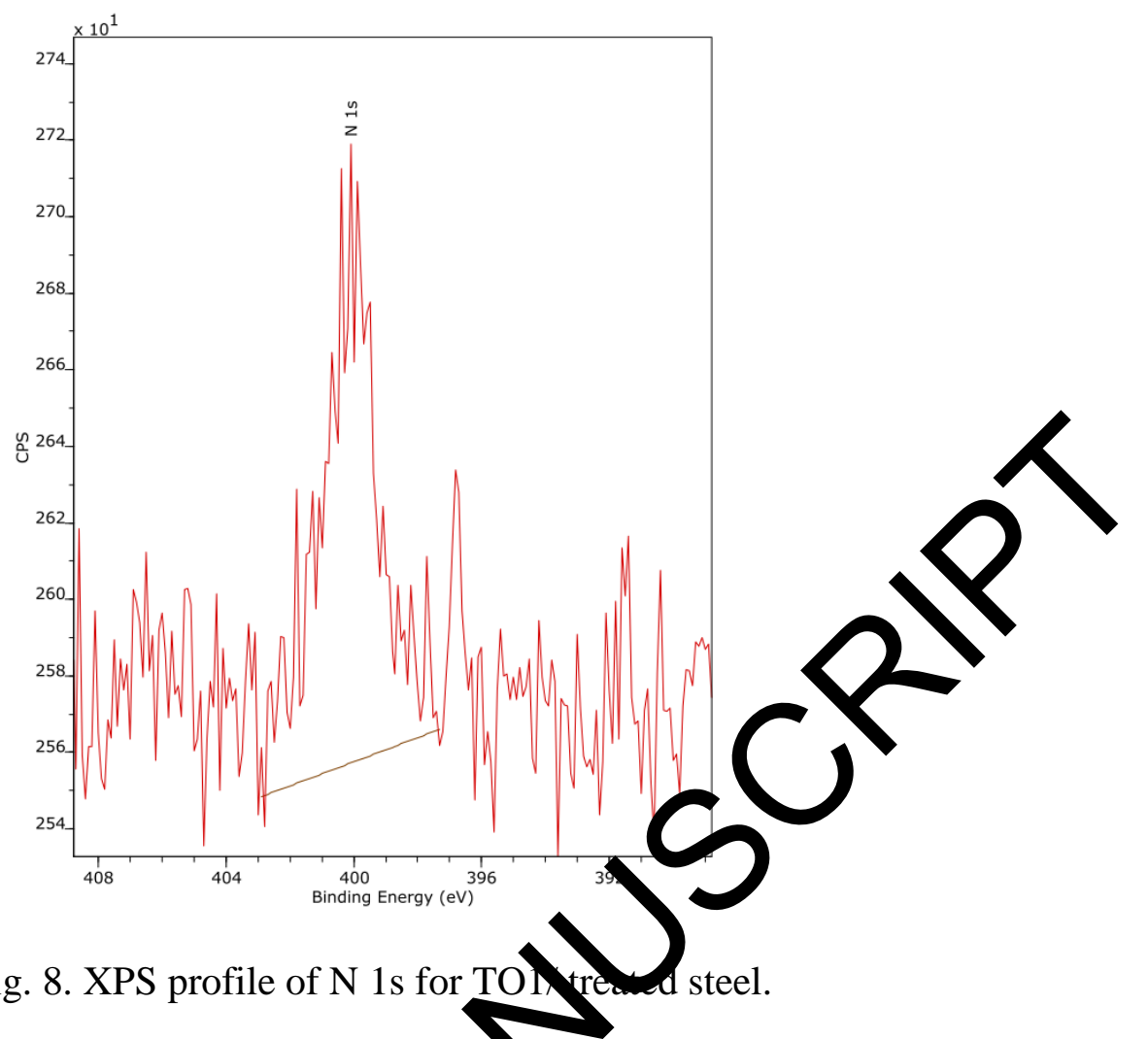

\subsection{Conclusion}

The results of inhibition of two compounds 1 and ST1) were studied in $1 \mathrm{M} \mathrm{HCl}$ for corrosion of C38 steel by differan me ods (weight loss and the electrochemical measurements). TO1 and ST1 good inhibitors with better efficiency for TO1. The compounds under inves classified as cathodic type inhibitors. The above conclusions were co firpled by EIS study where the charge transfer resistance increases and double layer cap langecreases as the concentration of the inhibitor increases. Adsorption of TO1 an ST on the C38 steel surface obeyed to the Langmuir isotherm. An XPS spectr ms nfirm that the adsorption of the two molecules was done through nitrogen and sul ar atoms.

\section{References}

1. F. Fadel, D. Ben Hmamou, R. Salghi, B. Chebli, O. Benali, A. Zarrouk, E. E. Ebenso, A. Chakir, B. Hammouti, Antifungal activity and anti-corrosion inhibition of 
origanum compactum extracts, Inter. J. Electrochem. Sci., 82013 (2013) 1101911032.

2. H. B. Ouici, M. Tourabi, O. Benali, C. Selles, M. Traisnel, C. Jama, F. Bentiss, R. Salghil, Experimental investigation on the corrosion inhibition characteristics of mild steel by 5-(2-hydroxyphenyl)-1,3,4-oxadiazole-2-thiol in hydrochloric acid medium. Journal, Mater. Environm. Sci., 7(8) (2016) 2971-2988.

3. H. B. Ouici, O. Benali, A. Guendouzi, Experimental and quantum chem tudies on the corrosion inhibition effect of synthesized pyrazole derivativ steel in hydrochloric acid, Res. Chem. Intermed., 42 (9) (2016) 7085- 09

4. H. B. Ouici, M. Tourabi, O. Benali, C. Selles, C. Kama, Zerrouk, F. Bentiss, Adsorption and corrosion inhibition properties 1, 3, 4-thiadiazole-2-thiol on the mild steel in hydrochloric acid me um: Thermodynamic, surface and electrochemical studies, J. Electroanal.

5. S. Gronowitz, in: S. Gronowitz (EN, The chemistry of heterocyclic compounds: thiophene and its derivarive vo 44, Wiley, (1991) New York, NY, USA, Part 3, (Chapter 2).

6. K. D. Hargr S F. K. Hess, J. T. Oliver, N-(4-Substituted-thiazolyl)oxamic acid derivati s. en reries of potent, orally active antiallergy agents. J. Med. Chem., 26 (8) 1983)1158-1163.

I. Hýtchinson, S. A. Jennings, B. R. Vishnuvajjala, A. D. Westwell, M. F. G. Stevens, Mntitumor Benzothiazoles. 16.1 Synthesis and Pharmaceutical Properties of Antitumor 2-(4-Aminophenyl)benzothiazole Amino Acid Prodrugs, J. Med. Chem., 45 (3) (2002) 744-747.

8. D. J. Kempf, H. L. Sham, K. C. Marsh, C. A. Flentge, D. Betebenner, B. E. Green, E. McDonald, S. Vasavanonda, A. Saldivar, N. E. Wideburg, W. M. Kati, L. Ruiz, C. 
Zhao, L. Fino, J. Patterson, A. Molla, J. J. Plattner, D. W. Norbeck, Discovery of ritonavir, a potent inhibitor of HIV protease with high oral bioavailability and clinical efficacy, J. Med. Chem., 41 (4) (1998) 602-617.

9. M. V. Nora de Souza, Synthesis and biological activity of natural thiazoles: An important class of heterocyclic compounds. J. Sulf. Chem., 26 (4-5) (2005) 429-449.

10. A. Rouf, C. Tanyeli, Bioactive thiazole and benzothiazole derivatives. Euron J. Nd. Chem., 97 (5) (2015) 911-927.

11. W. C. Patt, H. W. Hamilton, M. D. Taylor, M. J. Ryan, D. G. J Thyor, Structureactivity relationships of a series of 2-amino-4-thiazole-conta fing enin inhibitors, J. Med. Chem., 35 (14) (1992) 2562-2572.

12. R. N. Sharma, F. P. Xavier, K. K. Vasu, S. C. Clu uredi) S. S. Pancholi, Synthesis of 4-benzyl-1,3-thiazole derivatives as poteptial a inflammatory agents: an analoguebased drug design approach, J. Enzyme hil Med. Chem., 24 (3) (2009): 890-897.

13. A. A. Al-Sarawy, A. S. Fouda, M. S. El-Dein, Some thiazole derivatives as corrosion inhibitors for grbs stell in acidic medium, Desalination, 229 (2008) 279293.

14. M. Zebida, Q Be ali, $\diamond$. Maschke, M. Trainsel, Corrosion inhibition properties of 4methyl-2(m thy hio)-3- phenylthiazol-3-ium iodide on the carbon steel in sulfuric acid mediy m, Inter. J. Corros. Scale Inhib., 8(3) (2019) 613-627.

F. Y Cui, L. Guo, S.T. Zhang, Experimental and theoretical studies of 2-amino

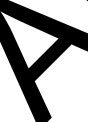
65 (2014) 1194-1201.

16. A. Döner, R. Solmaz, M. Özcan, G. Kardaş, Experimental and theoretical studies of thiazoles as corrosion inhibitors for mild steel in sulphuric acid solution, Corros. Sci., 53 (9) (2011) 2902-2913. 
17. T. Eicher, S. Hauptmann, A. Speicher, The chemistry of heterocycles: structure, reactions synthesis and applications, $2^{\text {nd }}$ Edition (2003) Wiley-VCH, Weinheim.

18. L. Guo, X. Ren, Y. Zhou, S. Xu, Y. Gong, S. Zhang, Theoretical evaluation of the corrosion inhibition performance of 1,3-thiazole and its amino derivatives, Arab. J. Chem., 10 (2017) 121-130.

19. C. Roussel, M. Adjimi, A. Chemlal, A. Djafri, Comparison of racemization noce in 1-arylpyrimidine-2-thione and 3-arylthiazoline-2-thione atropison and their oxygen analogs, J. Org. Chem., 53 (1988) 5076-5080.

20. C. Roussel, F. Andreoli, M. Roman, M. Hristova, N. Vant uyne New route to 3alkylthiazolo[3,2-a]benzimidazole derivatives, Molecus, 10 (J005) 327-333.

21. O. Benali, L. Larabi, B. Tabti, Y. Harek, Influent 1- hethyl 2-mercapto imidazole on corrosion inhibition of carbon steel in $5 \mathrm{M} \mathrm{H}_{2} \mathrm{SO}_{4}$, Anti-corros. Meth. Mater., 52 (5) (2005) 280-285.

22. F. Bentiss, M. Traisnel, M. Lagrenee The substituted 1,3,4-oxadiazoles: a new class of corrosion inhibitors gf mel in acidic media, Corros. Sci., 42 (1) (2000) 127146.

23. F. Mansfeld, N. Kending, S. Tsai, Recording and analysis of AC impedance data for corr sior studies. Corrosion, 38 (11) (1982) 570-580.

24. L. I arabi, O. Benali, Y. Harek, Corrosion inhibition of cold rolled steel in $1 \mathrm{M} \mathrm{HClO}_{4}$ solut ons by N-naphtyl N'-phenylthiourea. Mater. Lett., 61 (2007) 3287-3291.

B. Ouici, O. Benali, Y. Harek, L. Larabi, B. Hammouti, A. Guendouzi, Inhibition of mild steel corrosion in $5 \% \mathrm{HCl}$ solution by 5-(2-hydroxyphenyl)-1,2,4-triazole-3thione. Res. Chem. Intermed., 39 (2013) 2777-2793. 
26. O. Benali, L. Larabi, S. M. Mekelleche, Y. Harek, Influence of substitution of phenyl group by naphthyl in a diphenylthiourea molecule on corrosion inhibition of coldrolled steel in $0.5 \mathrm{M} \mathrm{H}_{2} \mathrm{SO}_{4}$, J. Mater. Sci., 41 (2006) 7064-7073.

27. O. Benali, A. Benikdes, D. Ben Hmamou, Adsorption and Corrosion Inhibitive Properties of 1-Methyl-1H-imidazole-2- thiol on Mild Steel in Acidic Environment, Pharm. Chem. J., 7(3) (2020) 56-68.

28. O. Benali, M. Zebida, U. Maschke, A. Attou, S. Bilgiç, Synthesis of 4 et lthiazol2(3H)-thione derivatives and their application as corrosion inhis loss, electrochemical, XPS and theoretical study, Appl. J. Envir. Eng.) Bci., 7(2) (2021) 125-143.

29 H. B. Ouici, O. Benali, Y. Harek, L. Larabi, B. Krnoy i, A. Guendouzi, The effect of some triazole derivatives as inhibitor for the corrosion of mild steel in $5 \%$ hydrochloric acid, Res. Chem. Interme 39 (2013) 3089-3103.

30 A. Attou, A. Benikdes, O. Benali, H.S Ouici, A. Guendouzi, Experimental studies on the corrosion inhibition 8 fee of $\mathrm{n}$ w synthesized pyrazole derivatives on C38 steel in $0.5 \mathrm{M} \mathrm{H}_{2} \mathrm{SO}_{4}$ and $\mathrm{L}$ 1 Jer. J. Chem. Biochem. Sci., 17 (2020) 120-128

31 F. Chaib ,H Al gli, O. Benali, Guido Flamini, Corrosion inhibition effects of the

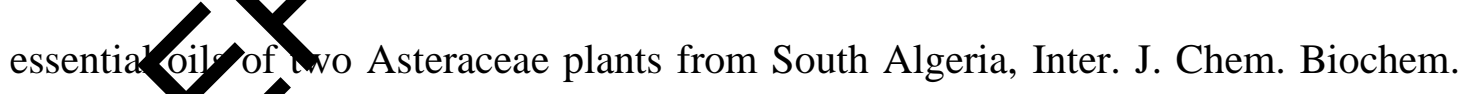
18(20):129-136.

M. Jeva, G. V. Prabhu, M. S. Boobalan, C. M. Rajesh,. Interactions and inhibition effect of urea-derived mannich bases on a mild steel surface in HCl. J. Phys. Chem., C, 119 (38) (2005) 22025-22043.

33 Z. Szklarska-Smialowska, J. Mankowski, Crevice corrosion of stainless steels in sodium chloride solution, Corros. Sci., 18 (11) (1978) 953 - 960. 
34 A. Yurt, S. Ulutas, H. Dat, Electrochemical and theoretical investigation on the corrosion of aluminium in acidic solution containing some Schiff bases, Appl. Surf. Sci., 253 (2) (2006) 919-925.

35 M. Hegde, S. P. Nayak, Synthesis, Characterization and study of new thiazole -2amine derivative as corrosion inhibitors for mild steel in $0.5 \mathrm{M} \mathrm{H}_{2} \mathrm{SO}_{4}$ solutign. $\mathrm{J}$. Chem. Pharm. Sci., 1 (2018)16-24.

36 C. J. Zou, X. L. Yan, Y. B. Qin, M. Wang, Y. Liu, Inhibiting evlua on of $\beta-$ Cyclodextrin-modified acrylamide polymer on alloy steel in sulfur Corros. Sci., 85 (2014) 445-454.

37 A. A. Farag, M. A. Migahed, E. A. Badr, Thiazo Ionid Liquid as Corrosion Inhibitor of Steel in $1 \mathrm{M} \mathrm{HCl}$ Solution: netrical, Electrochemical, and Theoretical Studies. Journal of Pio- nd Tribo-Corrosion (2019) 5:53. https://doi.org/10.1007/s40735-019-02-1/4

38 X Yang, F. Li, W. Zhang, 4-(Pyria -4-yl)thiazol-2-amine as an efficient nontoxic inhibitor for mild steel in hdrogloric acid solutions, RSC Adv., 2019, 9, 1045410464.

39 Z. Salarvand M Amirnasr, M. Talebian, K. Raeissi, S. Meghdadi, Enhanced corrosio re stase of mild steel in $1 \mathrm{M} \mathrm{HCl}$ solution by trace amount of 2-phenylben othia ole derivatives: Experimental, quantum chemical calculations and mole fular dynamics (MD) simulation studies, corrosion science 114 (2017) 133-145.

40 Z. Hu, Y. Meng, X. Ma, H. Zhu, J. Li, C. Li, D. Cao, Experimental and theoretical studies of benzothiazole derivatives as corrosion inhibitors for carbon steel in $1 \mathrm{M}$ HCl, Corrosion Science, 112 (2016) 563-575. 
41 N. Abdulwali1, F. Mohammed, A. Al subari, H. Ghaddar, A. Guenbour, A. Bellaouchou, E. Essassi, R. A. Cottis, Effect of Thiazole Derivatives on the Corrosion of Mild Steel in 1 M HCl Solution, Int. J. Electrochem. Sci., 9 (2014) 6402 - 6415

42 S. Xu, W. Li, X. Zuo, D. Zheng, X. Zheng, S. Zhang, Structural Origin of Corrosion Inhibition Effect over 2-(2- Hydroxyphenyl)benzothiazole on Steel in HCl Medjum, Int. J. Electrochem. Sci., 14 (2019) 5777 - 5793, doi: 10.20964/2019.06.20

43 R. Riga et J.J. Verbist, J. Chem. Soc. Perkin Trans., II, 1545 (1983).

44 A. Olsson, P. Agrawal, M. Frey et D. Landolt, Corros. Sci., 42, 12

45 M. Labrini, Synthèses et études physicochimiques de nouvaux thiadiazoles inhibiteurs de corrosion de l'acier en milieu acide, Thèse de doctorat, Université de des sciences et de technologie de Lille, 2005, Fraßc.

46 R. Devaux, D. Vouagner, A.M. De Becdolievr et C. Duret-Thual, Corros. Sci., 36, 171 (1994).

47 V. Di castro et S. Ciampi, Surf. Sci., \$1, 294 (1995).

48 T.L. Barr, J. Phys. Chem, $8 \mathbf{1 8 0}$ (1978).

49 A.S. Lima et A. At ens, Np. Phys., 51, 411 (1990).

50 A. P. Grosv 1 Br B. A. Kobe, M. C. Biesinger, N. S. McIntyre, Investigation of multiple spating of Fe 2p XPS spectra and bonding in iron compounds, Surf. Interf. And., 36 2004) 1564-1574.

J. G Dupin, D. Gonbeau, P. Vinatier, A. Levasseur, Systematic XPS studies of metal oxides, hydroxides and peroxides, Phys. Chem. Chem. Phys., 2 (2000) 13191324.

52 F. Moulder, W.F. Stickle, P.E. Sobol, K.D. Bomben, in: J. Chastain (Ed.), Handbook of X-Ray Photoelectron Spectroscopy, Perkin-Elmer Corp., Minnesota, USA, 1995. 


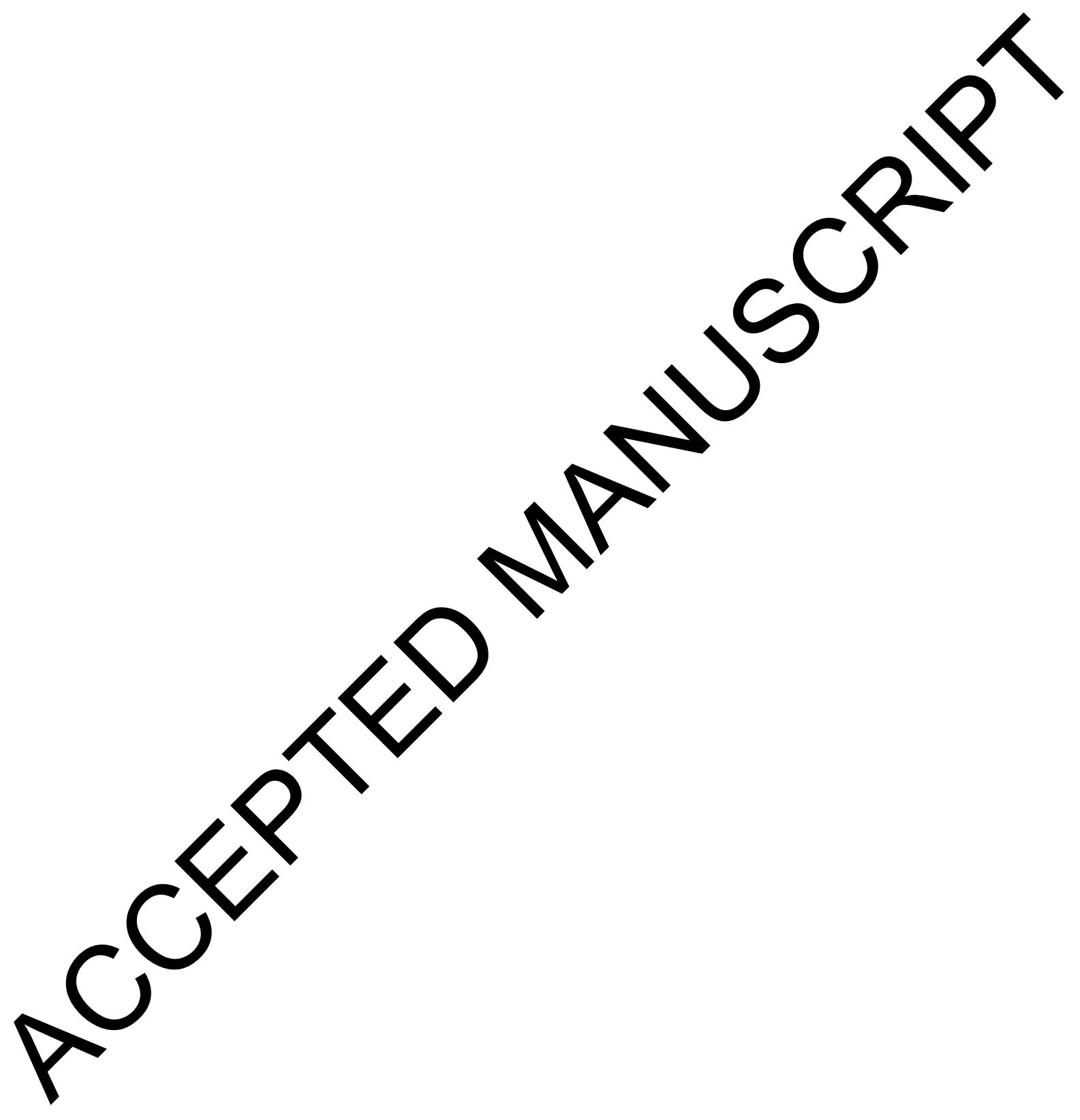

